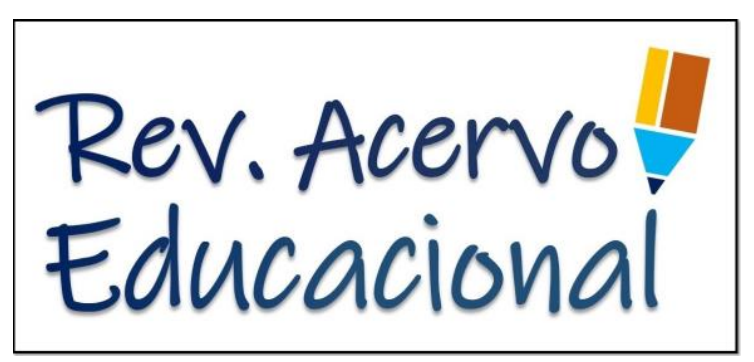

\begin{tabular}{c} 
ARTIGO DE REVISÃo \\
\hline Recebido em: 7/2019 \\
Aceito em: 7/2019 \\
Publicado em: 8/2019 \\
\hline
\end{tabular}

\title{
Educador: Despertando consciências
}

\author{
Educator: Awakening Consciousness
}

Educador: Despertando las conciencias

Gilberto Junior Silva Lima1*, Luciana Teles Moura².

\begin{abstract}
Resumo: Esse artigo buscou discutir a valorização e a importância do educador consciente nas construções na arte de ensinar. Pautados na essência do amor e do comprometimento com o que se faz, encarnado em si os valores do que se acredita. Trata-se de uma revisão bibliográfica de caráter teórico sobre o educador e suas práticas. O artigo avalia ainda a força do amor na educação como forma de despertar consciências, ampliar a percepção e ofertar a cada aprendiz uma transformação.
\end{abstract}

Palavras-chave: Educador, Consciência, Comprometimento, Amor.

\begin{abstract}
This article sought to discuss the value and importance of the conscious educator in constructions in the art of teaching. Guided by the essence of love and commitment to what is done, embodied in itself the values of what is believed. It is a bibliographical review of a theoretical nature about the educator and his practices. The article also evaluates the power of love in education as a way to awaken consciences, to increase the perception and to offer each learner a transformation.
\end{abstract}

Keywords: Educator, Consciousness, Commitment, Love.

Resumen: Este artículo buscó discutir el valor y la importancia del educador consciente en las construcciones en el arte de la enseñanza. Guiados por la esencia del amor y el compromiso con lo que se hace, encarnan en sí mismos los valores de lo que se cree. Es una revisión bibliográfica de carácter teórico sobre el educador y sus prácticas. El artículo también evalúa el poder del amor en la educación como una forma de despertar la conciencia, aumentar la percepción y ofrecer una transformación a cada alumno.

Palabras clave: Educador, La conciencia Compromiso, El amor

1 Bacharel em Direito pelas Faculdades Integradas do Extremo Sul da Bahia (UNESULBAHIA), Eunápolis, BA, Mestre em Gestão Social, Educação e Desenvolvimento Regional pela Faculdade Vale do Cricaré (FVC), São Mateus-Espírito Santo. Professor Titular de graduação nas áreas de Direito Constitucional, Direito Administrativo e Direito Internacional. *E-mail: pro.gir@gmail.com

2 Doutora e Mestre pela Universidade Federal do Espírito Santo (UFES), Vitoria, ES. Professora Titular de graduação e pós-graduação nas áreas de Administração, Psicologia, Educação e Comunicação Social.

*E-mail: lucianatmoura@gmail.com 


\section{INTRODUÇÃO}

O ensino superior requer amor e atenção, exige do corpo docente o planejamento e o adequado manejo das técnicas de ensino, dos recursos humanos, alteridade no olhar dentre outros. Acrescenta-se ainda aos fatores emocionais para a compreensão do que se ensina, não como imperativo da mente, mas reconstruindo os caminhos de sua curiosidade, assim consciente, sensível, emocionado, se abrira para o conhecimento (FREIRE P, 2001). Dessa forma, rotineiramente o corpo docente enfrenta desafios para que a transmissão de seus conteúdos ocorram conforme planejado, visando assim ampliar as percepções da mente e demonstrar que com amor conseguimos vencer os desafios, nos aproximar com carinho, ser amigo, compreensivo, honesto e justo com o aprendiz (CUNHA MI, 1989).

Nesse sentido, vem sendo demonstrado aqui os pilares conceituais para que cada professor construa seu próprio método de comunicação eficiente. Os autores apresentados nos mostram as chaves que abrem o imaginário do aprendiz, fazendo-o mais receptivo ao que é transmitido. Quando o professor realmente nos seu ensinar, encarna os valores em que acredita e os transforma em qualidades, o ensino flui amplamente (PERISSE G, 2011).

A educação com firme propósito no amor é discussão recorrente entre a doutrina na arte do ensinar, assim, verificou-se a importância em trazer os conceitos que julgados mais relevantes aqui se encontram. Isso levanta diversas percepções e atenções para o amor, comprometimento, felicidade, alteridade, sentimentos, transformação e acima de tudo o cuidado com o outro (CUNHA MI, 1989; HENDRICKS H, 1991; ALVES R, 1994; FREIRE P, 2006).

Justifica-se o presente artigo em virtude do aumento de profissionais carentes em se comprometer com causa do ensino-aprendizagem, falta de compromisso com o próximo (FREIRE P, 2006). Encarnando então os valores e pilares do amor no ensino, torna-se mais simples e eficaz esse comprometimento. Após a absorção dos conceitos aqui apresentados pelo professor/leitor será possível alterar o mecanismo do seu planejamento e ações diante dos enfrentamentos na caminhada do ensinar.

\section{MÉTODOS}

O método aqui abordado é a revisão bibliográfica, conforme Chiara ID (2008) a revisão busca alcançar um conhecimento já disponível sobre teorias, analisando-as ou explicando-as de acordo com o seu objeto investigada, com diversas finalidades.

Nesse sentido, vem comprovar e conhecer os argumentos sobre o amor na educação ditos por Rubem Alves, Paulo Freire, Moacir Gadotti, Howard Hendricks, Gabriel Perissé, Maria Isabel Cunha, Silvino José Fritzen, Marcos Tarcisio Masetto, Maria Lucia Marconde Carvalho Vasconcelos e Regina Helena Pires de Brito.

\section{REVISÃO BIBLIOGRAFICA}

O educador desperta consciências e as encaminham à imortalidade, porque é através dos seus aprendizes que de alguma forma este educador permanecera vivo, e enquanto os seus ensinos forem replicados ali também estará (ALVES R, 1994). Nesse sentido, através da palavra o educador tem o potencial de despertar consciências, ampliar percepções e trazer nas suas práticos diárias os ideais que são gerados pelo amor.

O amor é algo sublime, e em sua essência é a perfeição, é por si o diálogo e o compromisso com o próximo (FREIRE P, 2006). A chave então é comprometer-se com amor, os que ainda não compreenderam o valor da missão de ensinar, desperte sua autoconsciência e ensine com amor. Quando aquele que ensina ama o que faz, o processo de ensino-aprendizagem flui e segundo as autoras Vasconcelos e Brito (2006) é assim que os envolvidos no processo se aperfeiçoam. Arte de aperfeiçoar-se a algo é aprimorar o que já se sabe, sentido no coração o pulsar da vida. 
Segundo Cunha MI (1989) conseguimos assim ser amigo, compreensivo, honesto e justo com o aprendiz, tendo em vista o alto impacto das relações interpessoais e precariedade nas comunicações que ainda há no processo de ensino-aprendizagem.

Para Freire P (2006) o amor então abre as portas da percepção e a ressignificação acontece, é preciso que os aprendizes atribuam novo significado aos seus dias e ao que se aprende e como se aprende. $\mathrm{Na}$ visão de Arantes VA (2003) é necessário que o educador transforme sentimentos, emoções e o afeto do aprendiz em objeto de ensino-aprendizagem, uma tarefa que precisa ser bem planejada, arquiteta pelo próprio educador. O ensino-aprendizagem para Hendricks H (1991) é algo conjugado, ligado por hífen. Os dois termos são inseparáveis. Se o aluno não aprende, isso significa que nós não ensinamos. Em outras palavras, ensinar é levar alguém a aprender. Por isso a importância do comprometimento com a causa, a importância do amar o que faz, a importância de despertar consciência, despertar porque jaz adormecido estão muitos acadêmicos, que vivem dias sem perspectivas e concluem o ensino superior sem horizonte.

Ao educador é dada a missão de gerar reflexões, aguçando o imaginário do aprendiz, ofertando percepções do que se aprende e como se aprende. Assim, conforme Perissé G (2011) os valores que acreditamos devem se encarnar em nós e se transformar em qualidades, que serão transmitidas ao decorrer do tempo para o aprendiz. O acreditar na educação com base no amor precisa ser algo nítido em nossa consciência, quando o é, transportamos nossos aprendizes a caminhos positivos.

Segundo Hendricks H (1991) a ideia não é causar uma boa impressão e sim causar impacto. Não é convencer e sim transformá-lo. Nesse sentido, não devemos usar máscaras sociais e que desviam a realidade, é preciso examinar e compreender as palavras de Howard Hendricks, o que é impactar? O que é transformar? Fica o exame. Para Alves R (1994) todos devem passar por um processo de melhoria educador e educando, a qual ele chama de aperfeiçoamento, como já dito anteriormente por Vasconcelos MLMC e Brito RHP (2006).

Ainda para Alves R (1994) ensinar com amor é ensinar com felicidade, é preciso contagiar os aprendizes e fazer com que eles sintam o mesmo prazer daquele que lhes ensina algo. Se tu não tiveres encarnado a felicidade de fazer o que fazer, como que poderás exigir a felicidade do outro? $\mathrm{O}$ amor unido a felicidade, propiciam um estágio positivo de transformação. Se o educador com amor educa, os aprendizes aprenderão a amar a própria vida, e que em alguns casos darão motivo e o sentido para própria existência, porque a vida precisa fazer sentido.

Perissé G (2011) nos chama atenção para olharmos neste ponto a educação emocional, uma necessidade latente de fazer o educando refletir e compreender suas emoções e reações, fazendo-o acreditar em si mesmo e em suas capacidades de uma forma geral.

Sobre educação emocional, temos um conselho de Fritzen SJ (2000) aonde aduz que ouvir é importante. Possuem implicações dos fatores intelectuais e emocionais, e que seu objetivo só seria atingido quando as partes envolvidas no processo compreendessem por completo a mensagem. Assim, segundo Hendricks $\mathrm{H}$ (1991) quanto maior o nível de envolvimento dos aprendizes com comunicação eficaz, maior será o volume apreendido. Quanto mais pontos em comum com os aprendizes, melhor será a comunicação.

Segundo Gadotti M (2002) o educador que tem amor e paixão pelo o que faz precisa levar em conta as características próprias e individuais de cada aluno, as suas paixões, esperanças, conflitos. Preciso então se torna conhecer o outro, princípio da alteridade, se colocar no lugar do outro. Afirma ainda que o educador não é aquele que reproduz os sermões prontos e acabados, mas aquele que desperta consciência, motiva para a existência.

Neste sentido Freire P (2006) aduz que quando o educador ama o que faz, consegue ter a condição de olhar melhor os eventos que surgem à sua volta e resolvem com maior facilidade os conflitos, porque sua visão se torna espacial e não unidirecional.

Por fim, merece relevância a crítica que Gadotti M (2002) faz aos currículos escolares de uma forma geral, aduz que eles estão cheios de lições sobre o poder e vazios de lições sobre o amor. 
Uma possível resposta a esta crítica vem de Hendricks H (1991) a quase uma década, afirmando que o ensino que realmente causa impacto é aquele que passa de coração para coração. O educador é o modelo de profissional que muitos educandos esperam ser no futuro, a sabedoria e as competências adquiridas precisam estar sintonia para haver uma fina e clara harmonia.

\section{CONSIDERAÇÕES FINAIS}

Esse artigo se propôs, como objetivo geral, elaborar um conjunto de pensamentos sobre o amor e a educação, sua união e a capacidade de despertar consciências, ampliando percepções. Assim, trazendo uma luz nas tratativas entre educador e aprendiz. O educador então precisa ser a luz que clareara as consciências, pois com amor coisas extraordinárias vêm.

\section{REFERÊNCIAS}

1. ALVES R. A alegria de ensinar. 3 ed. ARS poética editora Itda, 1994.

2. ARANTES VA. Afetividade, cognição e moralidade na perspectiva dos modelos organizadores do pensamento. In: (org.). Afetividade na escola: alternativas teóricas e práticas. São Paulo: Summus, 2003. p. 109-128.

3. CHIARA ID. et al. Normas de documentação aplicadas à área de Saúde. Rio de Janeiro: Editora E-papers, 2008.

4. CUNHA MI. O bom professor e sua prática. Campinas: Papirus, 1989.

5. FREIRE P. Pedagogia do Oprimido. 43.ed. Rio de Janeiro: Paz e Terra, 2006a.

6. FRITZEN SJ. Janela de Johari. Petrópolis: Ed. 17. Vozes 2000.

7. GADOTTI M. Pensamento pedagógico brasileiro. 7. ed. São Paulo: Atica, 2002.

8. HENDRICKS H. Ensinando para transformar vidas. Ed. Betânia, Venda Nova, MG.

9. MASETTO MT. Competência pedagógica do professor universitário. São Paulo: Summus, 2003.

10. PERISSÉ G. O valor do Professor. Belo Horizonte: Autêntica Editora, 2011.

11. VASCONCELOS MLMC, BRITO RHP. Conceitos em educação em Paulo Freire: glossário. Petrópolis, RJ: Vozes, 2006. 